\title{
Electric coagulation method and treatment of the experimental study of landfill leachate
}

\author{
Bing Wang ${ }^{1, \text { a }}$, Jiani $\mathrm{Li}^{1, \mathrm{~b}}$,Lan Fang ${ }^{1, \mathrm{c}}$, Shouhui Tong ${ }^{1, \mathrm{~d}}$, and Dahai You ${ }^{1,2, \mathrm{e}}$
}

${ }^{1}$ Municipal \& Environmental Engineering College, Shenyang Jianzhu University, Shenyang 110168, China

\author{
${ }^{2}$ Liaoning Dayanghe Harbor Industrial Area ,Xiuyan 114319,China \\ a190867112@qq.com, ${ }^{\text {b } 850100297 @ q q . c o m, ~}{ }^{\mathrm{c}} 1183252339 @ q q . c o m,{ }^{\mathrm{d}} 1173762615 @ q q . c o m$, ,youd \\ ahai_1@126.com
}

Keywords: Electric coagulation, Garbage leachate, COD.

\begin{abstract}
Garbage leachate high concentrations of organic matter is considered difficult to deal with wastewater ,The complex and changeable water quality makes traditional processing method difficult to achieve better treatment effect. So the electric coagulation method processing technology application becomes inevitable trend. Using $\mathrm{Fe}$ as the anode and $\mathrm{C}$ as the cathode to treat leachate of a certain garbage in electric coagulation depth processing, and explore the electrolysis time, initial PH value, plate spacing and current density effect of the treatment effect. Results show that when the initial PH value was 6 , plate spacing was $3 \mathrm{~cm}$ and current density was $9 \mathrm{ma} / \mathrm{cm} 2$, electrolysis $60 \mathrm{~min}$ reached optimal effect, the COD removal rate was $84.5 \%$ and the TSS removal rate was $69.2 \%$.
\end{abstract}

\section{Introduction}

With the continuous development of society and improvement of people's living standards, environmental pollution of landfill leachate come along[1].Currently the common methods of landfill leachate treatment are biological method, chemical precipitation method and wetland method, etc[2,3],these methods have better treatment effect,but there are also many relevant issues,even be re-contaminated environment[4-6].Therefore, landfill leachate treatment new technologies research and analysis, research and application of it has become relevant departments urgent to think of topics[7-9].Compared with the conventional treatment methods,electric coagulation method requires no additional agents,the reaction time is shorter,the sludge production is less and the treatment efficiency is higher.In recent years it has been widely used in various types of wastewater treatment,and is worthy of further study[10].

\section{Experimental device and analytical method}

\subsection{Water sample parameters and emissions standards}

Each parameter content of water samples and the corresponding emission standards as shown in the following table:

Table 1 content of water samples and the emission standards

\begin{tabular}{|c|c|c|}
\hline index & $\begin{array}{c}\text { content } \\
(\mathrm{mg} / \mathrm{L})\end{array}$ & emission standard \\
\hline PH & 6.5 & $6 \sim 9$ \\
\hline COD & 324 & 100 \\
\hline TSS & 150 & 70 \\
\hline
\end{tabular}




\subsection{Experimental apparatus and experimental methods}

\subsubsection{Experimental apparatus}

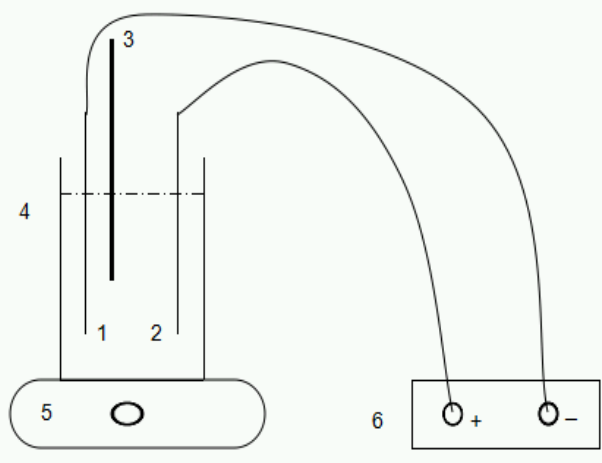

Fig. 2-1 Experimental apparatus

1 - cathode 2 - anode 3 - 3 - thermometer
6- D- DC stable constant current power supply

\subsubsection{Experimental methods}

Electric coagulation process also is known as electrolytic flocculation method[11].It refers to aluminum or iron as an electrode,In the role of DC,the anode is dissolution,produces flocculation ions,then through a series of hydrolysis, polymerization (and ferrous oxide) and other processes,the colloidal impurities and suspended impurities in the water take place flocculation and precipitation and separate[12].Electric coagulation process is mainly through electrolysis of metal anode (used as $\mathrm{Fe}, \mathrm{Al}$ and other low-potential metal electrode), in the role of DC, The anode is dissolution,produce $\mathrm{Fe}^{2+}, \mathrm{Al}^{3+}$ ions, $\mathrm{Fe}^{2+}, \mathrm{Al}^{3+}$ hydrolysis and polymerize in the solution,form various hydroxyl complexes,and then form polymer polynuclear hydroxyl complexes and hydroxide,these polynuclear hydroxyl complexes and hydroxide can make colloidal impurities and suspended impurities in wastewater flocculation precipitation and separated from water[13].

\section{Results and analysis}

\subsection{The impact on the treatment effect of operation time}

In conditions of iron anode,room temperature,The initial PH value of 6 and current density of 0.2A operations $60 \mathrm{~min}$, the impact on removal rate of electrolysis time is shown in Figure 3-1,COD and TSS removal rate increased with electrolysis time.After electrolysis 40min, increase in removal rate started slowing down,50min beginning to stabilize.The growth of electrolysis time was conducive to reaction fully,so removal rate increased. Therefore, we choose as a operation time of $60 \mathrm{~min}$.

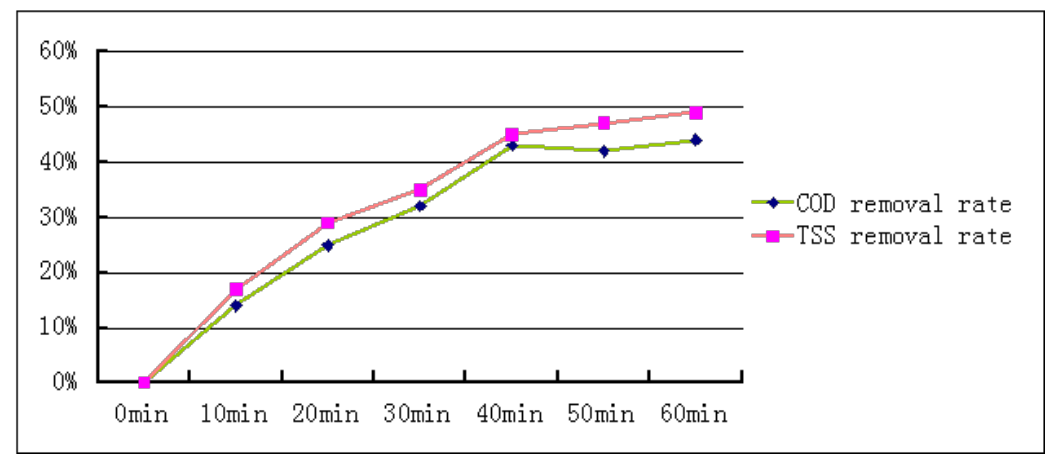

Fig. 3-1 The impact on removal rate of electrolysis time 


\subsection{The impact on the treatment effect of $\mathrm{PH}$ value of water samples}

The experimental water samples $\mathrm{PH}$ solution,initial $\mathrm{PH}$ value are respectively 2,3,4,5,6,7,in conditions of electrolysis time of $60 \mathrm{~min}$ and current density of $11 \mathrm{~mA} / \mathrm{cm}^{2}$ experimental research the impact on the treatment effect of $\mathrm{PH}$ value of water samples, the results are shown in Figure 3-2.

Although it can demulsify under acid condition,but does not utilize production of flocs.According to experiments,under strong acid conditions,COD and TSS removal rate was not high,under weakly acid conditions (PH about 6), COD and TSS removal rate reached the highest.At this time COD removal rate was $78.7 \%$, TSS removal rate was $61.0 \%$.

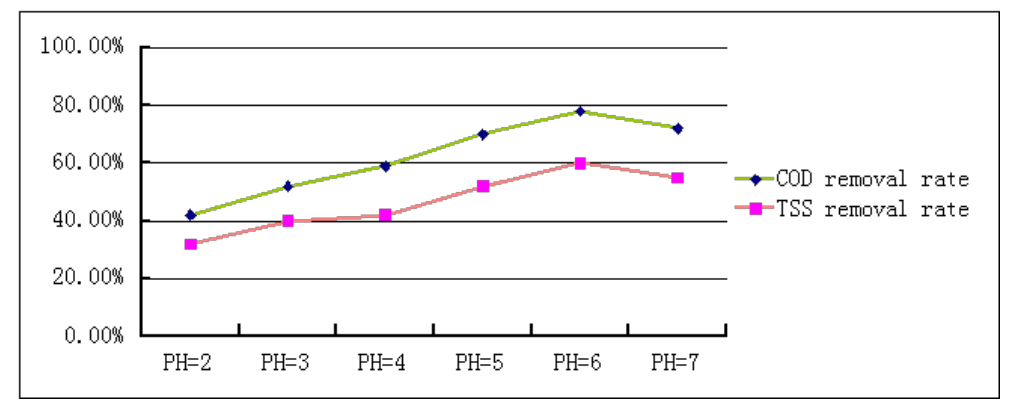

Fig. 3-2 The impact on the treatment effect of initial $\mathrm{PH}$ value

\subsection{The impact on the treatment effect of current density}

In conditions of iron as the anode and graphite as the cathode,adjusting the initial $\mathrm{PH}=6$, plate spacing of $3 \mathrm{~cm}$,current density of $3 \mathrm{~mA} / \mathrm{cm}^{2}, 5 \mathrm{~mA} / \mathrm{cm}^{2}, 7 \mathrm{~mA} / \mathrm{cm}^{2}, 9 \mathrm{~mA} / \mathrm{cm}^{2}, 11 \mathrm{~mA} / \mathrm{cm}^{2}, 13$ $\mathrm{mA} / \mathrm{cm}^{2}$.After an hour electrolysis,COD and TSS removal rates were respectively $48.5 \%$ 、 34.1\%;60.7\%,44.6\%;72.3\%,59.3\%;84.3\%,70.2\%;83.9\%,70.6\%;82.5\%,72.3\%.Obviously,as the current density increased COD and TSS removal rates were on the rise,especially the magnitude of the rise was larger when the current density was less than $7 \mathrm{~mA} / \mathrm{cm}^{2}$. When the current density reached $7 \mathrm{~mA} / \mathrm{cm} 2$, rising rate began slowing down.when $9 \mathrm{~mA} / \mathrm{cm}^{2}$, COD and TSS removal rates were stable, then the COD removal rate was $84.5 \%$, TSS removal rate was $69.2 \%$.

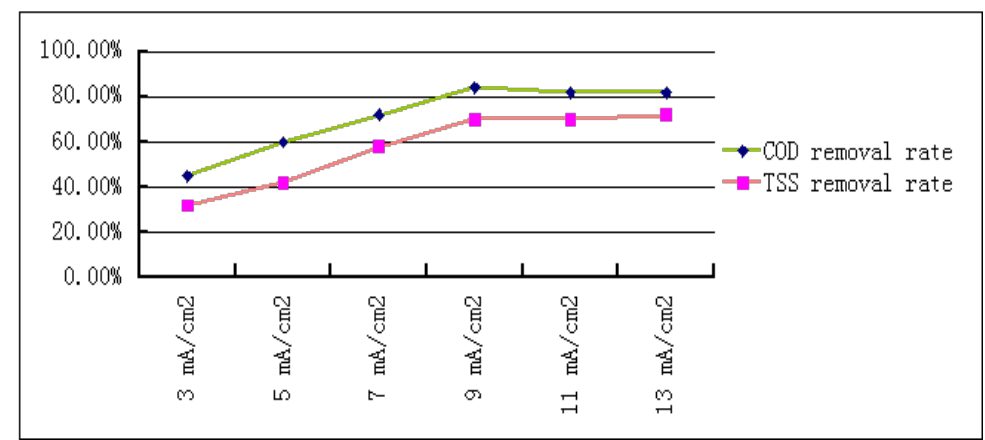

Fig. 3-3 The impact on the treatment effect of current density

\subsection{The impact on the treatment effect of plate spacing}

In conditions of iron as the anode and graphite as the cathode,adjusting the initial $\mathrm{PH}=6$,current density of $9 \mathrm{~mA} / \mathrm{cm}^{2}$, plate spacing of $2 \mathrm{~cm}, 3 \mathrm{~cm}, 5 \mathrm{~cm}, 7 \mathrm{~cm}$.After an hour electrolysis,COD and TSS removal rates were respectively $60.2 \%, 48.1 \% ; 82.4 \%, 64.3 \% ; 57.8 \%, 52.6 \% ; 50.5 \%, 38.2 \%$. Obviously,small plate spacing was conducive to the removal of COD and TSS in the solution .However, when the plate spacing was less than $3 \mathrm{~cm}$ removal rate was not high.The reason is plate spacing is too large or too small is not easy to mixing and diffusion of solution and the formation of flocs .Therefore I suggest to select $3 \mathrm{~cm}$ as the plate spacing . 


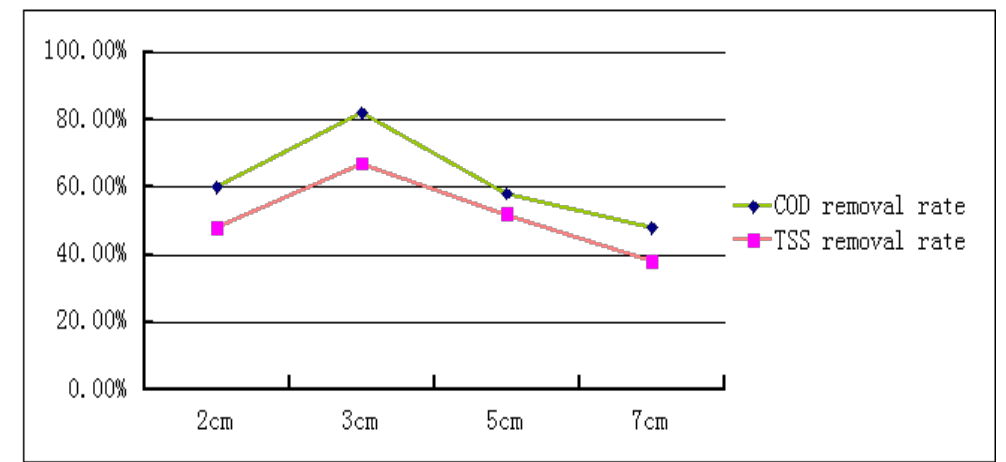

Fig. 3-4 The impact on the treatment effect of plate spacing

\section{Conclusion}

1. Electric coagulation process of landfill leachate both for removal of COD and TSS have better results. And the device is simple and small footprint,material is convenient and available,operation time is short,ideally suited for oilfield produced water treatment of remote areas.

2. Using $\mathrm{Fe}$ as the anode and $\mathrm{C}$ as the cathode,adjust the water sample the initial $\mathrm{PH}$ value of 6 , current density of $9 \mathrm{~mA} / \mathrm{cm}^{2}$, plate spacing of 3cm, electrolysis 1 hour,treatment effect is relative to the best.Sewage meets Secondary emission standards.

\section{References}

[1] Bingqing Zhao,Sheng Chen,Dezhi Sun,Jong Shik Chung. Fenton.Advanced treatment of refractory organic matter in landfill leachate[J]. Journal of Harbin Institute of Technology. 2007(08) [2] Yunping Yang,Jinjing Tang,Fang Fang,Jinsong Guo. UV/TiO2/Fenton.Research on photocatalytic oxidation of landfill leachate[J]. China Water \& Wastewater. 2006(07)

[3] W.C.Ying,R.R.BonK,S.A.SOjka.Treatment of landfill leachate in powdered activated carbon enhanced,sequencing batch bioreactors.Environmental progress. ENVDJ . 1987

[4] Guangming Zhang,Jiquan Zhou,Xihui Zhang,Minsheng Wu. Research of ultrasonic treatment refractory organics parameters affecting $[\mathrm{J}]$. Environmental pollution control technology and equipment. 2005(05)

[5] D.Geenens.Combined ozone-actived sludge treatment of landfill leachate. Water Science and Technology .

[6] Jinxi Wang,Qing Chang,Yajun Wang. Research of heavy metal flocculant MAPEI applied to copper electroplating wastewater[J]. Electroplating \& Pollution. 2008(03)

[7] Wenping Xue,Fude Xue,Lili Jiang,Ruijuan Fu,Liangliang Chu,Xiaoxia Wang,Hongjie Ma. Advances and review in treatment of wastewater containing cyanide[J]. Gold. 2008(04)

[8] Jiehong Cheng,Eryang Li. Landfill leachate of Fenton oxidation pretreatment[J]. Urban Environment \& Urban Ecology. 2003(03)

[9] Yuesheng Zhang,Zhihui Luan,Panming Wei,Kun Zhao. Activated carbon -H2O2 catalytic oxidation treatment of landfill leachate[J]. China Water \& Wastewater.. 2003(01)

[10] Mingyan Shi,Fuyi Cui,Hailong Zhang,Shouzhi Sun. Low temperature and turbidity contaminated water treatment optimization of coagulant[J]. Industrial Water Treatment. 2002(10)

[11] Borazacconi L,Gaxxala A,Ottonello G,et al.Denitrification in a nitrogen removal system of leachate trcatment:performance of upflow sludge blanket reactor. Water Science and Technology . 1999

[12] H.TIMUR,I.OZTURK.Araerobic sequencing batch reactor treatment of landfill leachate. Water Research . 1999

[13] Shide Liu.Baosheng Sun,Jingyun Liu. Experiment Study electroplating wastewater treatment technology[J]. Industrial Water Treatment. 2010(03) 